ORIGINAL ARTICLE

\title{
Non-collision injuries in public buses: a national survey of a neglected problem
}

\author{
P Halpern, M I Siebzehner, D Aladgem, P Sorkine, R Bechar
}

Emerg Med J 2005;22:108-110. doi: 10.1136/emj.2003.013128

See end of article for authors' affiliations

....................

Correspondence to:

Dr P Halpern, Emergency

Department, Tel Aviv

Sourasky Medical Center,

6 Weizman Street, Tel Aviv

64239, Israel;

dr_halperin@tasmc.health. gov.il

Accepted for publication 8 May 2004
Objectives: This prospective, nationally representative, multi-centre study was undertaken to assess noncollision injuries sustained by public bus passengers in Israel.

Methods: The emergency departments (EDs) of six medical centres, which participated in this eight month study, were chosen to represent both urban and rural catchment areas. All patients diagnosed with injuries sustained on a public bus not involved in a road traffic accident were promptly evaluated for mechanism and nature of injury and demographic parameters.

Results: The study cohort consisted of 120 patients (86 were female, 34 were male, age range 3-89 years). Over half were older than 55 years. The most common injuries were to the limbs, vertebral column, and head. The major mechanism of injury was acceleration/deceleration. Most patients were standing when they sustained the injuries. There were no fatalities, and 17 patients were admitted to hospital $(9$ of $17,52 \%$ older than 55 years). Extrapolation to yearly national statistics suggests a probable total of 729 such injuries.

Conclusion: The significant injuries inflicted on passengers of public buses not involved in road traffic accidents warrant decisive preventative measures by transportation authorities.
W had previously conducted a prospective study on 100 consecutive patients with injuries sustained on public buses, not associated with road traffic accidents (RTA), who were treated at the Emergency Department (ED) of the Tel-Aviv Sourasky Medical Center over an eight month period in 1998. ${ }^{1}$ Eight of these patients required hospitalisation and one patient died because of severe head injury. Most members of that study cohort were older than 60 years of age. The main mechanism for injury was deceleration/acceleration of the vehicle. We felt that better definition of the injury patterns and mechanisms of injury will be very helpful in producing preventative measures to minimise such morbidity, for example, by making design changes to buses or by changing driving habits and seating arrangements in public buses. Extrapolating from our data to fit the national scene, we calculated that there might be as many as 2700 such injuries annually in Israel, representing an alarmingly high level of morbidity. We have now examined this aspect of bus transportation safety nationwide.

\section{METHODS}

The study was conducted in the EDs of six medical centres throughout the country, three of which were urban (Tel Aviv, Jerusalem, Beer Sheva) and the other three were rural but close to intercity highways (Ashkelon, Ramat Gan, Naharia). The hospitals chosen represented a balanced geographical distribution as well as the two major types of bus transportation (urban compared with intercity). A questionnaire was distributed to these centres, and patients admitted to their EDs because of non-collision injury sustained on a public bus were evaluated prospectively. Data collection was performed during the period of March to October 2000. One nurse in each ED was assigned to gather the centre's data for this study and another nurse coordinated the information collected from the different centres. Frequent communication with research assistants, chart reviews, as well as monetary inducements were used to ensure maximal catchment of relevant patients.

\section{RESULTS}

The study cohort consisted of a total of 120 patients, 86 females $(71.7 \%)$ and 34 males $(28.3 \%)$ whose ages ranged from 3 to 89 years. Most of the patients (55.8\%) were older than 55 years (table 1 ).

Seventy patients $(58.3 \%)$ were treated at the ED of the Tel Aviv Sourasky Medical Center. There was no difference in the occurrence of injury between the days of work throughout the week. The low number of incidents during weekends (Friday and Saturday for Israel) probably reflects the fact that only limited public transportation is available in most cities. Most of the injuries were incurred during inner city trips, and $90 \%$ of them occurred during the daytime (table 2 ).

Most of the injuries (55.8\%) were sustained by passengers who were either standing or moving in the bus (table 3 ), and the major mechanism of injury was sudden deceleration or acceleration (table 4).

The most common injuries were to the limbs (33.3\%), followed by the head (29\%) and the spine (22\%) (table 5).

Seventeen patients (14.2\%) were admitted to hospital, of which four were orthopaedic admissions: two for pelvic fractures, one for a calcaneal fracture with subsequent operative correction, and one for radial fracture, (9 of 17, $52 \%$ older than 55 years). The mean length of hospital stay was 2.4 days, range $2-5$ days. There were no deaths.

\section{DISCUSSION}

In our earlier study, ${ }^{1}$ we had evaluated non-collision injuries in buses, a mechanism of trauma hitherto unreported in the medical literature although recognised epidemiologically in the road safety literature..$^{2-5}$ These patients had been treated at our ED in Tel Aviv. The alarming level of morbidity that emerged motivated us to extend this investigation to six representative medical centres throughout the country. Together, these centres had provided care to 604983 patients from a total of 2444548 ED visits in the entire country throughout 2000. Extrapolating from these numbers, the probable total yearly injury burden may be as high as 729 ( $2444548 / 604983 \times 12$ months/8 months of the study). 


\begin{tabular}{|lll|}
\hline $\begin{array}{l}\text { Table 1 } \\
\text { passengers }\end{array}$ & \multicolumn{2}{l|}{ Age distribution of the injured bus } \\
\hline Age $(\mathbf{y})$ & Number & $\%$ \\
\hline$\leq 18$ & 8 & 6.7 \\
$19-34$ & 22 & 18.3 \\
$35-54$ & 23 & 19.2 \\
$55-74$ & 43 & 35.8 \\
$75+$ & 24 & 20.0 \\
\hline
\end{tabular}

\begin{tabular}{|c|c|c|}
\hline Hour & Number & $\%$ \\
\hline $0500-1200$ & 53 & 44.2 \\
\hline $1200-1900$ & 55 & 45.8 \\
\hline $1900-2300$ & 12 & 10.0 \\
\hline
\end{tabular}

The assumptions in this extrapolation are that seasonal injury rates do not vary (a fair assumption as there is no clear variation in public bus use) and that the medical centres chosen for the study represent the rest of the nation (an admittedly unproved assumption). As Tel Aviv seems to have a disproportionate number of injuries, the national number may be slightly lower, but still a source of considerable concern. We believe that the combination of the participating centres provides an adequate sampling of the injuries cared for at all EDs in Israel, and that extrapolation is applicable.

Most of the injuries occurred to passengers who were standing and while the bus was in motion. The principal mechanism was sudden acceleration or deceleration of the vehicle, followed by boarding and alighting from the bus. The disproportionate number of victims over the age of 75 years clearly targets this population as being most vulnerable to such events.

A study by the British Department of Transport ${ }^{2}$ looked at injuries occurring in various types of vehicles in Great Britain between 1994 to 1998. There were an overall total of 8774 injuries per year, or 0.7 injuries per bus per year, for 6183 buses and coaches. Nineteen injuries $(0.2 \%)$ were fatal, 625 $(7.1 \%)$ were serious, and $8130(92.7 \%)$ were slight. Of the two categories of killed or seriously wounded people that comprised $644(7.3 \%)$ injuries, 403 incidents (62.6\%) were not attributable to impact-that is, unrelated to RTAs. Also, $48.8 \%$ of the killed or seriously injured casualties were not seated and the vehicle was not involved in a collision. Not surprisingly, non-collision incidents typically involved a single occupant of the vehicle as compared with an average of two for collision incidents. The incidence of injuries in decreasing order was highest for alighting, boarding, standing, and seated passengers. ${ }^{2}$ Noteworthy, these data included seated passengers and this may explain the difference in their

Table 3 Passenger location at the time of injury (total number $=120$ )

\begin{tabular}{lll}
\hline Position & Number & $\%$ \\
\hline Standing & 67 & 55.8 \\
Moving & 30 & 25.0 \\
Sitting & 23 & 19.2 \\
\hline
\end{tabular}

Table 4 Mechanism of the 120 injuries

\begin{tabular}{llr}
\hline Mechanism & Number & $\%$ \\
\hline Acceleration/deceleration & 63 & 51.2 \\
Boarding/alighting & 35 & 28.5 \\
Closing of doors & 6 & 4.9 \\
Bus swerving during & 9 & 7.3 \\
a turn & & \\
\hline
\end{tabular}

findings from ours. It also interesting that this comprehensive report found that non-collision injuries occurred mostly in urban areas with speed limits of $30 \mathrm{mph}$ (94\%), a higher proportion than the average of $83 \%$ for all injuries on buses. An Austrian study ${ }^{3}$ showed that $32 \%$ of the fatal and serious injuries that were incurred in buses were attributable to noncollision incidents; this figure was 50\% in Germany where $70 \%$ of cases were attributable to emergency braking and $72 \%$ of the casualties were older than 55 years. US data from reports of the American Public Transportation Association (APTA) Report ${ }^{4}$ and the Bureau of Transportation Statistics $(\mathrm{BTS})^{5}$ show an equally alarming number of injuries: there were 3205 in buses and 15850 in all forms of non-collision public transportation incidents. The BTS report for the year $2000^{5}$ listed 19847 non-collision motorbus incidents, including eight fatalities and 20967 injuries. Relative to the populations of the US and Israel, this number is lower than the extrapolated number for Israel (population ratios of $290542869 / 6600000=44$, injury ratios $20967 / 729=29$ ).

A study of the Dutch Institute for Road Safety from $1993^{6}$ found that some 2300 persons are treated in Dutch hospitals because injuries occurring in buses, of which 1200 were not involved in RTAs. DeGraaf and Van Weperen ${ }^{7}$ tested the ability of people to withstand acceleration in buses and trains by producing acceleration forces in four directions (forward, backwards, and laterally) on a treadmill in 22 healthy adults. They used acceleration energies of $0.3-1.6 \mathrm{~m} / \mathrm{sec}^{2}$ and found that the maximal acceleration at which subjects could still stand declines with age almost linearly. The researchers then looked at the accelerations occurring in public buses in the city of Amsterdam and found values of $1.0-2.0 \mathrm{~m} / \mathrm{sec}^{2}$. These numbers are significantly higher than the mean values at which most people can remain upright. It seems clear, therefore, that acceleration levels commonly encountered in public buses are greater than those at which an elderly person can keep their balance unless safely seated or holding on to a support. There are over 5000 buses in Israel, with 1900 of them serving municipal Tel Aviv. An average of 1.37 million passengers use public buses daily in the country (personal communication, Chairman of the Road Safety Commission, Ministry of Transportation, Israel). Most of the nation's buses are comparatively new, they have powerful engines, and they are capable of abrupt starts and stops.

There is also serious overcrowding of metropolitan buses and these vehicles are intentionally designed to have

\begin{tabular}{lcc}
\hline \multicolumn{2}{l}{ Table 5} & \multicolumn{2}{l|}{ Sites of the 120 injuries } \\
\hline Site & Number & $\%$ \\
\hline Limb & 62 & 33.3 \\
Head & 54 & 29.0 \\
Spine & 41 & 22.0 \\
Chest & 11 & 5.9 \\
Pelvis & 12 & 6.5 \\
Abdomen & 4 & 2.2 \\
Skin & 2 & 1.1 \\
\hline
\end{tabular}


comparatively few seats and more standing space. This results in a high proportion of passengers who must stand during some or the entire ride, especially during rush hours. Bus drivers' shifts include a fixed number of "runs", inevitably motivating them to end a run as fast as possible or, in other words, to drive as fast as possible.

Our data show that there is a need to improve safety of passengers in buses. Improvements have been suggested in several reports, such as that of the UK Department for Transport ${ }^{2}$ : that a minimum seat width be specified, that seat spacing be a minimum of $650 \mathrm{~mm}$ for all public transport vehicles to meet the needs of accessibility while minimising the reduction in seating capacity, that a minimum separation of $40 \%$ of the passenger compartment length of at least two doors be maintained regardless of which side the doors are fitted and whether or not the doors be service or emergency doors, that the emergency door step height be a maximum of $100 \mathrm{~mm}$, that gangway and floor slopes be limited to $8 \%$ maximum (thus avoiding the need to restrict the areas in which passengers may stand and assisting with the needs of mobility impaired passengers), that the area in which passengers may stand is no further forward than the rear or centre of the bus, and that handrail provision should be provided throughout the vehicle and not be limited to areas where passengers may stand. The British Vehicle Safety Research Centre report ${ }^{5}$ lists further suggestions, for example, texturing floors to prevent slips, prohibiting slopes greater than $3^{\circ}$ in the bus, minimising steps, adding visual cues to any floor obstructions, minimising the height of the initial step into and out of the bus, configuring the interior of the bus with minimal hard and sharp protrusions (much like what is already the case with private cars), and ensuring more lenient timetables for drivers that will obviate the need to hurry and thus reduce abrupt accelerations and decelerations. The same report stated that $90 \%$ of complaints from injured passengers put the blame on the driver, but it is also important to recognise that drivers are under considerable strain because high levels of traffic congestion, pressure to keep to timetables, and being the single operator of a complex machine. The legislators of the UK are to be congratulated for enacting a Public Service Vehicle Accessibility Regulations law (January 2001), which provides for improved access to buses and better overall design, such as low floors, priority seats, and space for wheelchairs.

A useful way to depict the potential interventions involved in managing this problem, is by using the Haddon injury prevention matrix (available on line http://www.emjonline. com/supplemental). ${ }^{8}$

Non-collision injuries in public buses cause significant bodily harm that is at least partly preventable with greater attention to bus design and operational details, and the relevant authorities are urged to take appropriate measures. Emergency physicians are urged to regard such injuries as potentially severe, and treat them accordingly, but also to consider reporting them to the relevant authority whenever there seems to be a correctable cause to the incident, such as driver misconduct or mechanical faults in the vehicle.

\section{ACKNOWLEDGEMENTS}

The authors thank Esther Eshkol for editorial assistance.

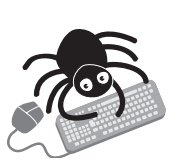

The Haddon injury prevention matrix is available on line (http://www.emjonline.com/supplemental).

\section{Authors' affiliations}

P Halpern, D Aladgem, P Sorkine, R Bechar, Department of Emergency Medicine, Tel Aviv Sourasky Medical Center, Sackler Faculty of

Medicine, Tel Aviv University, Tel Aviv, Israel

M I Siebzehner, The Gertner Institute for Epidemiology and Health Policy Research, Tel-Hashomer, Israel

Funding: this study was made possible by a generous grant from the Israeli Ministry of Transportation, Bureau of Road Safety. The opinions expressed in this manuscript are solely those of the writers and do not necessarily reflect the views of the Ministry of Transportation of Israel.

Conflicts of interest: none declared.

\section{REFERENCES}

1 Bachar R, Aladgem D, Sarov J, et al. Injuries due to falls in urban buses: 100 consecutive cases. Harefuah 1999;137:77-8, 86.

2 Kirk A, Grant R, Bird R. Bus and coach passenger casualties in non-collision incidents. Vehicle Safety Research Center, ICE ergonomics, Loughborough University, UK. (http://www.lboro.ac.uk/research/esri/vsrc/pdf\%20files/ Moscow\%20TS3C\%2OBus\%20Casualties\%20NonCollision\%20lncidents\%20AK\%20.pdf)

3 Kirk A, Grant R. ECBOS Task 1.1 Report Overview, European Commission 5th framework project number 1999-RD.11130, Feb 2001. (http://www.dsd.at/ ecbos.htm).

4 American Public Transportation Association. Report, table 71: safety summary by mode, 2000. (http://www.apta.com/stats/safety/ safesumm.htm).

5 Bureau of Transportation Statistics. Transportation profile-Nebraska, table 2-15. Washington,DC: US Transit Safety Data, 2000 (http://www.bts.gov/ publications/transportation_profile/nebraska/html/table_02_15.html).

6 Department for Transport. Vehicle standards and engineering research compendium of research projects 2000, theme 3: Bus/Coach Safety Project S170A/VE. (http://www.roads.dft.gov.uk/vehicle/vse/research/ compend2000/19.htm\#s170a).

7 DeGraaf B, Van Weperen W. The retention of balance: an exploratory study into the limits of acceleration the human body can withstand without losing equilibrium. Human Factors 1997;39:111-18.

8 Haddon W. A logical framework for categorizing highway safety phenomena and activity. J Trauma 1972;12:193-207. 